\title{
Intrapericardial carboplatin in the management of malignant pericardial effusion in breast cancer: a pilot study
}

\author{
Mie Kotake ${ }^{1} \odot \cdot$ Hisao Imai $^{1} \cdot$ Kyoichi Kaira $^{2} \cdot$ Tomomi Fujisawa $^{3} \cdot$ Yasuhiro Yanagita $^{3} \cdot$ Koichi Minato $^{1}$
}

Received: 4 April 2019 / Accepted: 15 June 2019 / Published online: 27 June 2019

(C) The Author(s) 2019

\begin{abstract}
Purpose Malignant pericarditis is observed in 5.1-7.0\% of all cases of acute pericarditis, and malignant pericardial effusion (MPE) can lead to cardiac tamponade in the later stages of cancer. Breast cancer is the second most common primary cancer associated with MPE, but the efficacy and safety of intrapericardial carboplatin (CBDCA) have never been evaluated in breast cancer. In this study, we assessed the clinical significance of intrapericardial CBDCA following catheter drainage in patients with breast cancer-related MPE.

Methods A catheter was inserted percutaneously into the pericardial space under echocardiographic guidance. After complete drainage, $150 \mathrm{mg}$ of CBDCA was instilled into the pericardial space through the catheter.

Results Eight patients with symptomatic breast cancer-related MPE were treated at the Gunma Prefectural Cancer Center, between July 2010 and March 2016. One month after treatment, 100\% of MPE was controlled. The median survival time from the recurrence of breast cancer until death or study follow-up was 2336 days (range 293-3937 days), while that from intrapericardial CBDCA administration until death or study follow-up was 552 days (range 35-1673 days). Grade 1 fever, nausea, hypotension, fatigue, and chest discomfort were observed in one patient (12.5\%) after intrapericardial CBDCA administration.

Conclusions We found that intrapericardial administration of CBDCA after catheter drainage appears to be safe and effective in managing breast cancer-associated MPE. As the number of patients in this study was small, further studies are warranted to determine the safety and efficacy of intrapericardial CBDCA in the management of breast cancer-related MPE.
\end{abstract}

Keywords Malignant pericardial effusion · Acute pericarditis · Breast cancer · Intrapericardial carboplatin · Catheter drainage

\section{Introduction}

Malignant pericarditis is observed in 5.1-7.0\% of all cases of acute pericarditis [1]. Malignant pericardial effusion (MPE) can develop into cardiac tamponade, which is a lifethreatening disorder $[2,3]$. Breast cancer is the second most

Mie Kotake

m10702012@gunma-u.ac.jp

1 Division of Respiratory Medicine, Gunma Prefectural Cancer Center, 617-1, Takahayashinishi, Ota, Gunma 373-8550, Japan

2 Department of Respiratory Medicine, Comprehensive Cancer Center, International Medical Center, Saitama Medical University, Saitama, Japan

3 Division of Breast Oncology, Gunma Prefectural Cancer Center, Ota, Japan common primary cancer associated with MPE [4]. Previous studies have demonstrated the efficacy of pericardiocentesis and extended catheter drainage is inadequate to prevent reaccumulation of MPE [5-7]. The intrapericardial instillation of various sclerosants such as tetracycline or doxycycline [8], tetracycline [9], cisplatin [10], thiotepa [11-13], mitomycin C [14], bleomycin [15], mitoxantrone [16, 17], minocycline [18], aclarubicin [19], and OK-432 [20] have been reported to be effective in controlling MPE. However, these studies examined a broad range of malignancies, and did not include a sufficient number of breast cancer patients with MPE to establish the most suitable sclerosants specific to this category. In several kinds of malignancies, including breast cancer, tetracycline, cisplatin, and thiotepa were effective, but caused serious complications [9-13]. The efficacy and safety of intrapericardial carboplatin (CBDCA) have never been evaluated in breast cancer. In this study, we assessed the 
clinical significance of intrapericardial CBDCA following catheter drainage in patients with breast cancer-related MPE.

\section{Patients and methods}

\section{Patients}

Patients with breast cancer-related symptomatic MPE were included in the study based on the following criteria: (i) symptoms caused by MPE histologically and/or cytologically defined as a result of breast cancer, (ii) 20 years of age or older, (iii) ECOG performance status (PS) $0-3$, and (iv) white blood cells $\geq 2000 / \mathrm{mm}^{3}$, hemoglobin $\geq 8.0 \mathrm{~g} / \mathrm{dL}$, Platelets $\geq 50,000 / \mathrm{mm}^{3}$, aspartate aminotransferase (AST)/ alanine amino transferase (ALT) $<5$ times upper limit of normal (ULN), total bilirubin $<3$ times ULN, and creatinine $<3$ times ULN. Patients were excluded based on serious comorbidity, pregnancy or lactation, active infections, or coagulation disorders.

\section{Treatment method}

A catheter was inserted percutaneously into the pericardial space under echocardiographic guidance. After the effusion was completely drained, $150 \mathrm{mg}$ of CBDCA dissolved in $20 \mathrm{ml}$ saline was instilled into the pericardial space through the drainage catheter. The catheter was then clamped and reopened after $2 \mathrm{~h}$. When the drainage volume reached less than $50 \mathrm{ml} / \mathrm{day}$, the catheter was removed. In cases where the catheter could not be removed within 7 days of treatment, CBDCA was administered a second time.

\section{Statistical analysis}

Clinical characteristics, MPE control rate at 1 month after treatment, recurrence, complications, survival, time-todrainage tube removal, and toxicity were assessed based on medical records. Toxicity was judged according to Common Terminology Criteria for Adverse Events (CTCAE) version 4.0. We used a Kaplan-Meier analysis of time-to-event data to estimate median event times. All analyses were performed using GraphPad Prism 8. The protocol complied with the Declaration of Helsinki. Our institution approved this study and all patients provided written informed consent.

\section{Results}

\section{Patient characteristics}

Eight patients with breast cancer-related symptomatic MPE were treated at the Gunma Prefectural Cancer Center between July 2010 and March 2016. Their characteristics and treatment outcomes are shown in Table 1. All were women with a median age of 59 years (range 47-73) who had previously received surgery. Six patients had invasive ductal carcinoma, one had invasive lobular carcinoma, and one had invasive mucinous carcinoma. Seven patients $(87.5 \%)$ were diagnosed as having positive estrogen receptors (ER) and five (62.5\%) were diagnosed as having human epidermal growth factor receptor 2 (HER2). Seven patients $(87.5 \%)$ had a PS of $2-3$, and one $(12.5 \%)$ had a PS of 1 before the insertion of the catheter. CBDCA was administered once in seven patients and twice in one patient.

\section{Efficacy}

The median duration of pericardial drainage was 7 days (range 5-20 days). The control rate of MPE at 1 month after this treatment was $100 \%$. All patients had a PS of $0-1$ after the removal of the catheter, and were discharged from hospital and survived 1 month after intrapericardial CBDCA administration. After the control of MPE, six patients received systemic therapy, with four receiving chemotherapy, four receiving hormonal therapy, and one receiving targeted therapy. The median duration from the instillation of CBDCA until the start of systemic therapy was 18 days (range 7-134 days) among four patients, while two continued systemic therapy during our study. The median survival time from the recurrence of breast cancer until death or study follow-up was 2336 days (range 293-3937 days) (Fig. 1). The median survival time from the intrapericardial CBDCA administration until death or study follow-up was 552 days (range 35-1673 days) (Fig. 2).

\section{Adverse events}

Grade 1 fever, nausea, hypotension, fatigue, and chest discomfort were observed in one patient $(12.5 \%)$ after intrapericardial administration of CBDCA. These were managed by supportive therapy. No patient experienced chest pain or arrhythmia, and we observed no significant complications or deaths resulting from treatment.

\section{Discussion}

Malignant pericardial effusion is a potentially fatal complication of cancer. To our knowledge, this is the first study evaluating the efficacy and safety of intrapericardial administration of CBDCA to manage MPE in the patients with recurrent breast cancer. Moriya et al. [21] showed that the administration of $300 \mathrm{mg}$ of CBDCA to the pericardial space in patients with non-small cell lung cancer (NSCLC) is effective for the control of MPE, with management achieved 


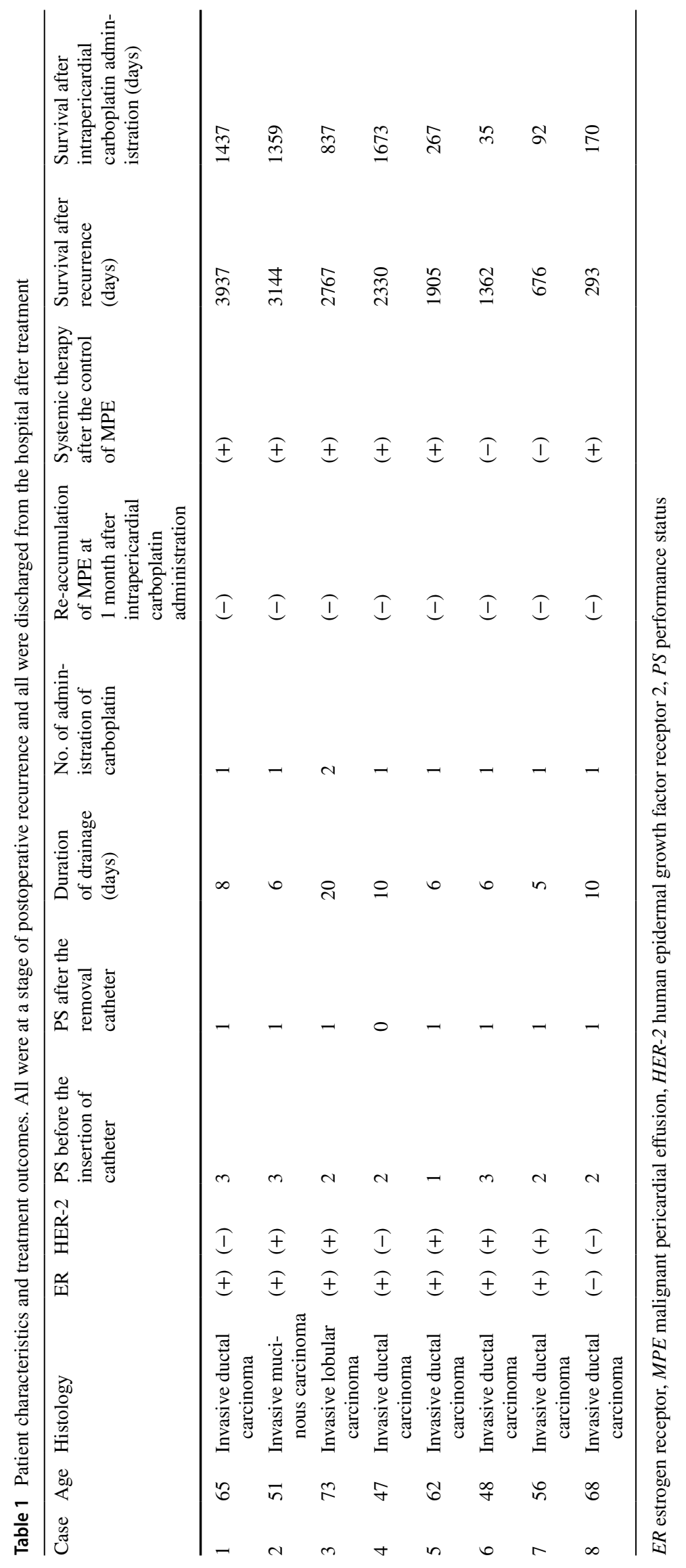




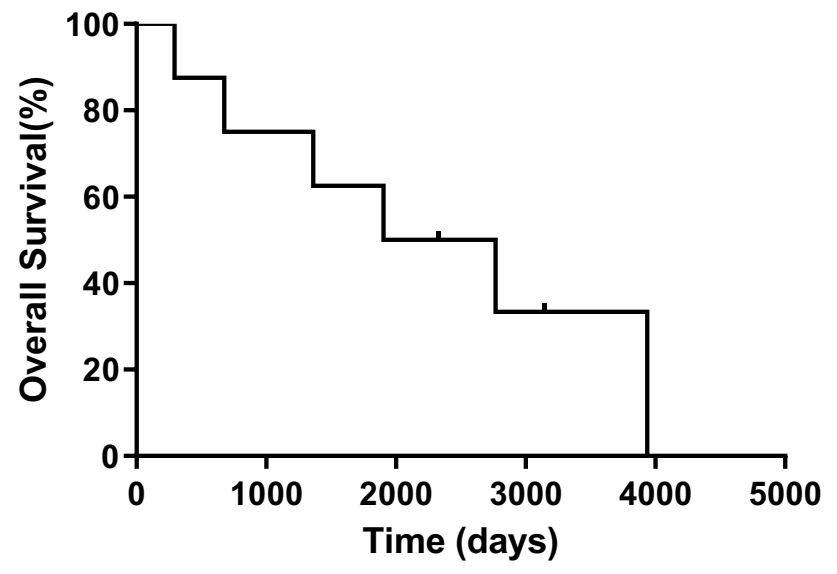

Fig. 1 Survival time after recurrence of breast cancer until death or study follow-up. The median survival time from the recurrence of breast cancer until death or study follow-up was 2336 days $(n=8)$

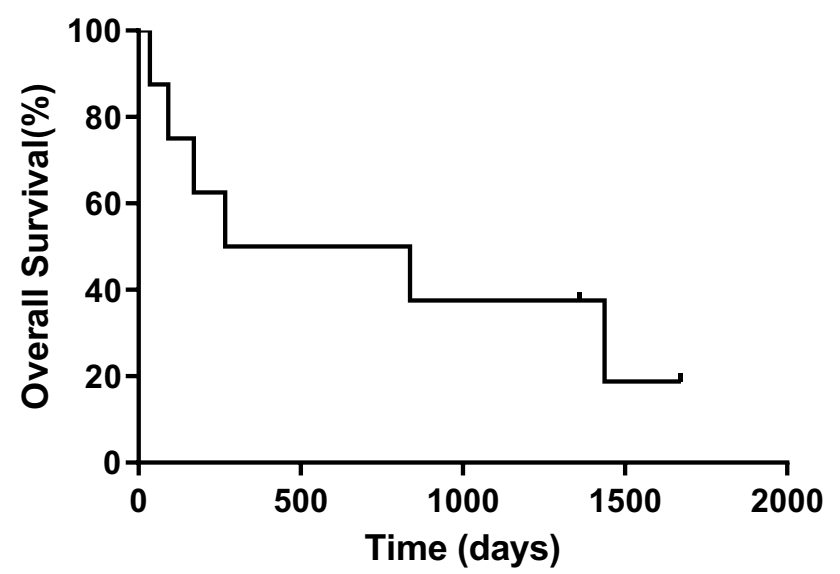

Fig. 2 Survival time after intrapericardial carboplatin administration until death or study follow-up. The median survival time from the intrapericardial carboplatin administration until death or study followup was 552 days $(n=8)$

in nine out of ten patients. Their methods involved instilling $300 \mathrm{mg}$ CBDCA and $100 \mathrm{mg}$ lidocaine dissolved in $50 \mathrm{ml}$ normal saline through the drainage catheter into the pericardial space, after which the catheter was clamped, then reopened after $40 \mathrm{~min}$. In the present study, $150 \mathrm{mg}$ CBDCA dissolved in $20 \mathrm{ml}$ normal saline was infused via catheter, followed by clamping for $2 \mathrm{~h}$. This dose was selected to suit the small body size of our patients (43.5-69.2 kg body weight). We also selected a longer clamping time due to the previous study's finding that the high concentration of CBDCA in the pericardial effusion was enough to kill cancer cells $1.5 \mathrm{~h}$ after reopening the catheter, and that a low concentration of CBDCA in the plasma resulted in management of MPE with little systemic toxicity. This would help to ensure that intrapericardial CBDCA administration is suitable in patients for whom systemic chemotherapy is not appropriate.

In the present study, six patients received systemic therapy after the control of MPE with few adverse events, and the median survival time from the intrapericardial CBDCA administration until death or study follow-up was 552 days, which is longer than previous studies $[4,8-14,17,19]$ (Table 2). Patients with improved PS due to pericardial sclerosis received progressed systemic chemotherapy, contributing to the long survival time after intrapericardial CBDCA administration until death or study follow-up. Median duration of drainage was 9.5-10.5 days in NSCLC [21, 22]. Duration of drainage in the present study was comparable to that reported in previous studies.

Apodaca-Cruz et al. [5] reported a recurrence rate after pericardiocentesis as high as $33 \%$ in patients with MPE, including those with breast cancer. The recurrence rate of percutaneous prolonged catheter drainage in patients with MPE including breast cancer is $12-75 \%[6,7]$. However, the safety and efficacy of intrapericardial bleomycin compared with pericardial drainage have only been evaluated in lung cancer patients. In these patients, survival with MPE control (effusion failure-free survival, EFFS) at 2 months was not significantly different in patients with drainage alone versus intrapericardial bleomycin (29\% versus $46 \%$, one-sided $P=0.086$ according to Fisher's exact test) [23]. The recurrence rate of intrapericardial bleomycin for MPE, including breast cancer, was high (22.2\%) and three patients (16.7\%) developed severe complications [15]. In Table 2, we list trials evaluating pericardial sclerosis as management of MPE. Thiotepa, tetracycline, and cisplatin are capable of controlling 82.6-100\% of MPE, but are associated with severe complications. Mitomycin C, bleomycin, and minocycline have been shown to have some efficacy. In this study, no patients had re-accumulation of MPE 1 month after pericardial sclerosis, and none experienced severe adverse events related to intrapericardial CBDCA administration. On the basis of this, we suggest that carboplatin is a suitable sclerosant for management of MPE.

There are several limitations to this study. As this was a pilot study, we did not specifically evaluate late cardiac complications, and our small patient population did not permit a randomized study to compare intrapericardial administration of CBDCA versus pericardial drainage alone. However, pericardial effusions complicate $1.9 \%$ of disseminated breast cancer [24]. Because of this low incidence, it would be difficult to achieve a prospective study evaluating pericardial sclerosis in an adequate number of patients with a single malignancy.

In conclusion, we found that intrapericardial instillation of CBDCA after catheter drainage appears to be safe and effective for the management of MPE associated with breast cancer. However, as the number of patients in this study was small, a large-scale phase II study is warranted to compare 
Table 2 Pericardial sclerosis as management of malignant pericardial effusion in cancer patients, including those with breast cancer

\begin{tabular}{|c|c|c|c|c|}
\hline Sclerosant & References & $\begin{array}{l}\text { Successfully controlled/number of } \\
\text { patients with malignancy treated } \\
(\%)\end{array}$ & Adverse events & Median survival (range) \\
\hline $\begin{array}{l}\text { Tetracycline } \\
\text { or doxycy- } \\
\text { cline }\end{array}$ & Maher et al. [8] & $68 / 93(73.1 \%)$ & $\begin{array}{l}\text { Pain }(n=17) \text {, catheter plugged }(n=8) \text {, } \\
\text { fever }(n=7), \text { atrial fibrillation/flutter } \\
(n=6), \text { paroxysmal atrial tachycardia } \\
(n=2) \text {, development of rub }(n=2), \\
\text { cardiac arrest before sclerosis }(n=2), \\
\text { infection }(n=1)\end{array}$ & $\begin{array}{l}\text { All: } 98 \text { days }(1-1724) \text {, } \\
\text { breast cancer: } \\
131 \text { days }(6-1724)\end{array}$ \\
\hline Tetracycline & Shepherd et al. [9] & $50 / 58(86.2 \%)$ & $\begin{array}{l}\text { Pain }(n=9) \text {, fever }(n=5) \text {, atrial fibril- } \\
\text { lation/flutter }(n=4) \text {, catheter plugged } \\
(n=4) \text {, development of pericardial } \\
\text { friction rub }(n=2) \text {, paroxysmal atrial } \\
\text { tachycardia }(n=1)\end{array}$ & 133 days (3-1149) \\
\hline Cisplatin & Maish et al. [10] & $35 / 42(83.3 \%)$ & Myocardial ischemia $(n=1)$ & $2.8 \pm 1.3$ months \\
\hline \multirow[t]{3}{*}{ Thiotepa } & Bishiniotis et al. [11] & $19 / 19(100 \%)$ & $\begin{array}{l}\text { Atrial fibrillation }(n=2) \text {, vasovagal reac- } \\
\text { tion }(n=1)\end{array}$ & 330 days $(15-1040)$ \\
\hline & Martinoni et al. [12] & $30 / 33(90.9 \%)$ & None & $\begin{array}{l}\text { All: } 115 \text { days }(22- \\
\text { 1108), breast cancer: } \\
272 \text { days }(47-1108)\end{array}$ \\
\hline & Colleoni et al. [13] & $19 / 23(82.6 \%)$ & $\begin{array}{l}\text { Transient grade III thombocytopenia and } \\
\text { leukopenia }(n=1) \text {, grade I leukopenia } \\
(n=1)\end{array}$ & 4.5 months $(1-26)$ \\
\hline Mitomycin $\mathrm{C}$ & Lee et al. [14] & $14 / 20(70 \%)$ & Pericardial constriction $(n=1)$ & 101 days \\
\hline Bleomycin & Moya et al. [15] & $14 / 18(77.8 \%)$ & $\begin{array}{l}\text { Mild fever }(n=5) \text {, atrial fibrillation } \\
(n=3), \text { retrosternal pain }(n=1) \text {, infec- } \\
\text { tion }(n=1)\end{array}$ & Not reported \\
\hline \multirow[t]{2}{*}{ Mitoxantrone } & Musch et al. [16] & $15 / 16(93.8 \%)$ & $\begin{array}{l}\text { Loss of appetite }(n=1) \text {, leukocytopenia } \\
(n=1)\end{array}$ & Not reported \\
\hline & Norum et al. [17] & $2 / 5(40 \%)$ & Not reported & 122 days (28-294) \\
\hline Minocycline & Lashevsky et al. [18] & $10 / 14(71.4 \%)$ & $\begin{array}{l}\text { Severe chest pain }(n=7) \text {, pericardial } \\
\text { injury }(n=2) \text {, vasovagal reaction } \\
(n=1) \text {, transient fever }(n=1)\end{array}$ & Not reported \\
\hline Aclarubicin & Kawashima et al. [19] & $5 / 5(100 \%)$ & None & 26 days (13-354) \\
\hline OK-432 & Imamura et al. [20] & $3 / 3(100 \%)$ & High fever, chills, chest pain $(n=3)$ & Not reported \\
\hline Present study & & $8 / 8(100 \%)$ & $\begin{array}{l}\text { Fever }(n=1), \text { nausea }(n=1), \text { hypotension } \\
\quad(n=1), \text { fatigue }(n=1), \text { chest discomfort } \\
(n=1)\end{array}$ & 552 days (35-1673) \\
\hline
\end{tabular}

intrapericardial CBDCA administration with extended catheter drainage alone to manage MPE in breast cancer.

Acknowledgements We thank Drs. Takeshi Miyamoto and Akiko Morishita for their assistance in preparing this manuscript.

\section{Compliance with ethical standards}

Conflict of interest The authors declare that they have no competing interests.

Open Access This article is distributed under the terms of the Creative Commons Attribution 4.0 International License (http://creativeco mmons.org/licenses/by/4.0/), which permits unrestricted use, distribution, and reproduction in any medium, provided you give appropriate credit to the original author(s) and the source, provide a link to the Creative Commons license, and indicate if changes were made.

\section{References}

1. Imazio M et al (2007) Indicators of poor prognosis of acute pericarditis. Circulation 115:2739-2744

2. Press OW, Livingston R (1987) Management of malignant pericardial effusion and tamponade. JAMA 257:1088-1092

3. Spodick DH (2003) Acute cardiac tamponade. N Engl J Med 349:684-890

4. Gornik HL, Gerhard-Herman M, Beckman JA (2005) Abnormal cytology predicts poor prognosis in cancer patients with pericardial effusion. J Clin Oncol 23:5211-5216

5. Apodaca-Cruz A et al (2010) Effectiveness and prognosis of initial pericardiocentesis in the primary management of malignant pericardial effusion. Interact CardioVasc Thorac Surg 11:154-161

6. Patel N et al (2013) Retrospective comparison of outcomes, diagnostic value, and complications of percutaneous prolonged drainage versus surgical pericardiotomy of pericardial effusion associated with malignancy. Am J Cardiol 112:1235-1239 
7. Gatenby RA et al (1991) Percutaneous catheter drainage for malignant pericardial effusion. J Vasc Intervent Radiol 2:151-155

8. Maher EA, Shepherd FA, Todd TJ (1996) Pericardial sclerosis as the primary management of malignant pericardial effusion and cardiac tamponade. J Thorac Cardiovasc Surg 112:637-643

9. Shepherd FA et al (1987) Medical management of malignant pericardial effusion by tetracycline sclerosis. Am J Cardiol 60:1161-1166

10. Maisch B (2002) Neoplastic pericardial effusion. Efficacy and safety of intrapericardial treatment with cisplatin. Eur Heart J 23:1625-1631

11. Bishiniotis TS et al (2000) Malignant cardiac tamponade in women with breast cancer treated by pericardiocentesis and intrapericardial administration of triethylenethiophosphoramide (thiotepa). Am J Cardiol 86:362-364

12. Martinoni A et al (2004) Long-term results of intrapericardial chemotherapeutic treatment of malignant pericardial effusions with thiotepa. Chest 126:1412-1416

13. Colleoni M et al (1998) Intracavitary chemotherapy with thiotepa in malignant pericardial effusions: an active and well-tolerated regimen. J Clin Oncol 16:2371-2376

14. Lee LN et al (1994) Ultrasound guided pericardial drainage and intrapericardial instillation of mitomycin $\mathrm{C}$ for malignant pericardial effusion. Thorax 49:594-595

15. Moya I (2010) Efficacy and safety of intrapericardial bleomycin for malignant pericardial effusion. J Clin Oncol 28:e19687

16. Musch E et al (2003) Intrapericardial instillation of mitoxantrone in palliative therapy of malignant pericardial effusion. Onkologie 26:135-139
17. Norum J, Lunde P, Aasebo U, Himmelmann A (1998) Mitoxantrone in malignant pericardial effusion. J Chemother 10:399-404

18. Lashevsky I et al (1996) Intrapericardial minocycline sclerosis for malignant pericardial effusion. Chest 109:1452-1454

19. Kawashima O, Kurihara T, Kamiyoshihara M, Sakata S, Ishikawa S, Morishita Y (1999) Management of malignant pericardial effusion resulting from recurrent cancer with local instillation of aclarubicin hydrochloride. Am J Clin Oncol 22:396-398

20. Imamura $T$ et al (1989) Intrapericardial instillation of OK-432 for the management of malignant pericardial effusion: report of three cases. Jpn J Med 28:62-66

21. Moriya T, Takiguchi Y, Tabeta H, Watanabe R, Kimura H, Nagao K, Kuriyama T (2000) Controlling malignant pericardial effusion by intrapericardial carboplatin administration in patients with primary non-small-cell lung cancer. Br J Cancer 83:858-862

22. Kaira $\mathrm{K}$ et al (2005) Management of malignant pericardial effusion with instillation of mitomycin $\mathrm{C}$ in non-small cell lung cancer. Jpn J Clin Oncol 35:57-60

23. Kunitoh $\mathrm{H}$ et al (2009) A randomised trial of intrapericardial bleomycin for malignant pericardial effusion with lung cancer (JCOG9811). Br J Cancer 100:464-469

24. Woll PJ, Knight RK, Rubens RD (1987) Pericardial effusion complicating breast cancer. J R Soc Med 80:490-491

Publisher's Note Springer Nature remains neutral with regard to jurisdictional claims in published maps and institutional affiliations. 